\title{
Shear Property of AZ31B Magnesium Alloy Prepared by Solid -state Recycling
} \author{
WU Shuyan ${ }^{1, \mathrm{a}}$, JI Zesheng ${ }^{2, \mathrm{~b}, ~ *}$, HUANG Zhiqiu ${ }^{1, \mathrm{c}}$, WANG Tao ${ }^{1, \mathrm{~d}}$, LV Ying $^{1, \mathrm{e}}$ and HU Ming ${ }^{1, \mathrm{f}}$ \\ ${ }^{1}$ School of Materials Science and Engineering, Jiamusi University, Xuefu Street, Jiamusi, China \\ ${ }^{2}$ School of Materials Science and Engineering, Harbin University of Science and Technology, Linyuan \\ Street, Harbin, China \\ a wsy_hit@sina.com, ${ }^{\mathrm{b}}$ jizesheng@hrbust.edu.cn, ${ }^{\mathrm{c}}$ jmsdxclxy@163.com, ${ }^{\mathrm{d}}$ jmsdxwangtao@163.com, ${ }^{\mathrm{e}}$ \\ jmsdxclxy@163.com, ${ }^{f}$ jmsdxclxy@163.com \\ *corresponding author
}

Keywords: AZ31B magnesium alloy, solid-state recycling, extrusion ratio, shear strength, the bonding between chips

\begin{abstract}
AZ31B Magnesium alloy bars were prepared by solid-state recycling with different extruding ratio of $4: 1,11: 1,25: 1,44: 1$. Shear tests were conducted through designing and preparing shear specimens and fixture. The bonding between chips in recycled magnesium alloy by solid-state process was successfully characterized through measuring the shear strength along the extruding direction. The effect of extrusion ratio on the shear property of AZ31B magnesium alloys fabricated from chip was studied. In the investigated extrusion ratio range of $4: 1$ to $44: 1$, the shear strength along the extruding direction increases with the increasing extruding ratio. This is because recrystallization grain became small and mean, the bonding between chips converts from mechanical bonding to metallurgical bonding and the bonding between chips was enhanced when extruding ratio increase.
\end{abstract}

\section{Introduction}

Having many advantages such as excellent mechanical properties, low density, high dimensional stability and good machinability[1,2], magnesium alloys show great potential applications in aerospaces, automobiles[3,4]. However, massive waste chips would be produced in the process of machining since magnesium alloy showed good machinability. With the increasing application for magnesium alloys, recycling of waste chips attracts more and more attention[5].

For recycling magnesium alloy chips, an advanced recycling method in solid-state has been researched in Japan[6,7]. Compared with the re-melting process, solid-state recycling shows its advantages because it can reduce the oxidation loss and energy consumption in the re-melting process without special environmental protection. The recycled AZ80[8], AZ91[9] and Mg-Al-Ca alloy[10] processed by solid-state method showed high strength, ductility and superplasticity. Zhao et al.[11] reported the recycling of Mg-Zn-Y-Zr alloy chip and studied the influence of the recycling process on microstructure and tensile properties of the recycled alloys. The previous researchers demonstrated the feasibility of the solid-state recycling.

During the extruding, Magnesium chips consolidate each other under the act of high temperature and compression stress. The bond between chips is the significant factor affecting the mechanical properties of recycled alloy. Microstructure and tensile properties of recycled magnesium alloy prepared by different recycling process have been studied, However, the bond between magnesium alloy chips in recycled alloy was not investigated.

The aim of this work is to characterize the bond between magnesium alloy chips through measuring the shear strength along the extrusion direction and analyze the effect of extruding ratio on it. 


\section{Experimental procedures}

The employed material in this work was a deformable AZ31B magnesium alloy(Mg-2.9 wt\%Al$1.0 \mathrm{wt} \% \mathrm{Zn}-0.35 \mathrm{wt} \% \mathrm{Mn})$. Chips were prepared by machining an as-received ingot in a lathe. The size of chip was $8-10 \mathrm{~mm}$ in length, $2 \mathrm{~mm}$ in width and $0.4 \mathrm{~mm}$ in thickness, as shown in Figure 1.

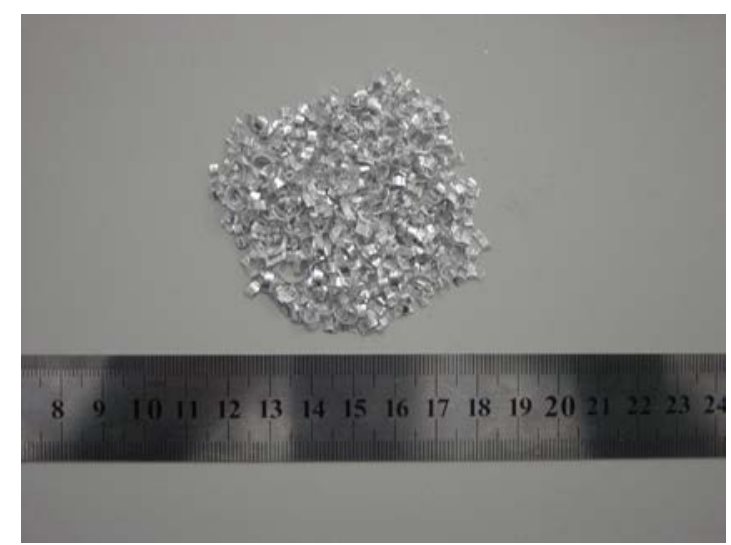

Figure 1 AZ31B Magnesium alloy chips

The chips were filled into the cylindrical mold with a diameter of $40 \mathrm{~mm}$ and were cold-pressed into billet using the method of unilateral pressing, the pressure and the holding time was $350 \mathrm{MPa}$ and 1 minute, respectively. The mold with the formed billet was heated to $673 \mathrm{~K}$ and holded for 20 minutes. Then hot extrusions were preformed in air at an extrusion rate of $0.2 \mathrm{~mm} \mathrm{~s}-1$. Four extrusion ratios of 4:1,11:1, 25:1 and 44:1 were used respectively.

Shear test was designed through machining shear specimens by linear cutting and preparing a fixture by welding. Shear force is parallel to the extruding direction. Shear specimens were shown in Figure 2. Shear tests were carried out with an initial strain rate of $3 \times 10^{-3} \mathrm{~s}^{-1}$ on WDW-10 electron universal testing machine. Shear strength of recycled alloys were measured for extrusion ratios of $4: 1,11: 1,25: 1,44: 1$.

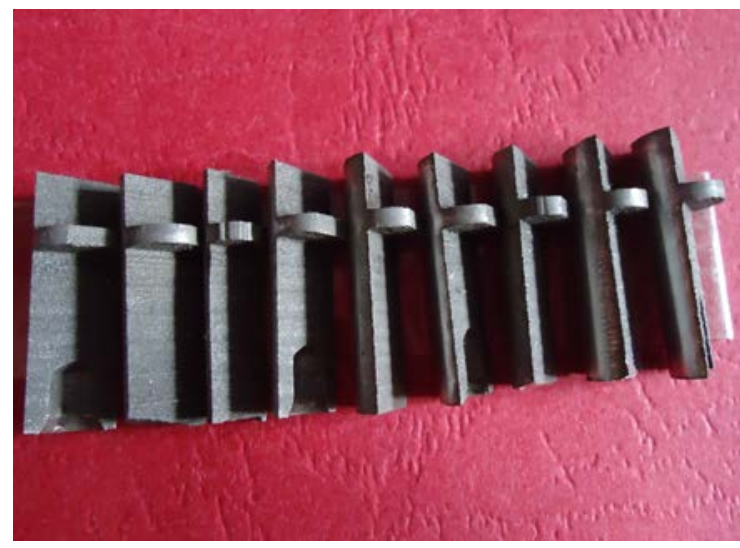

Figure 2 Shear specimens

\section{Results and Discussion}

\subsection{The shear strength of recycled AZ31B magnesium alloy with different extruding ratios}

Table 1 illustrates the shear strength of recycled specimens with different extruding ratios. It can be seen that the shear strength is low with the extruding ratio of $4: 1$. The shear strength of recycled specimen increases gradually when the extruding ratio increases from 4:1 to 44:1.

The reason is that with the increasing of extruding ratio, the degree of dynamic recrystallization increased, so the size of grain became small and mean, as reported in previous research [12]. On the other hand, when the extruding ratio increases, the stress of magnesium alloy chips increased, the 
combination between chips was reinforced during the extruding. With the lower extruding ratio, the bonding between chips depended mainly on mechanical bonding. When the extruding ratio increases, metallurgical bonding was formed. The two reasons result in the improved mechanical property of the recycled magnesium alloy with the increase of extruding ratio.

Being similar with fiber reinforced metal matrix composite, magnesium alloy chips in compressed billet arrange grossly along the extruding direction after the hot extrusion. Interfaces between chips in recycled magnesium alloy are mostly parallel to the extruding direction. Therefore, the shear strength along the extruding direction can be used to characterize the bonding between chips in recycled alloy.

Table 1 The shear strength of recycled specimens with different extruding ratios

\begin{tabular}{|c|c|}
\hline extruding ratio & The shear strength/MPa \\
\hline 4: 1 & 94.28 \\
\hline 11: 1 & 114.35 \\
\hline 25: 1 & 125.63 \\
\hline 44: 1 & 139.28 \\
\hline
\end{tabular}

\subsection{Fracture Morphology}

Figure 3 shows the fracture morphology under the shear force of recycled specimens with different extruding ratios. There are obvious deformation marks and microcracks along the shear force direction on the fracture surface. In the process of shearing test, stress concentration will be produced around the oxide, and induce the microcracks formation and propagation, which will result in the shear fracture.
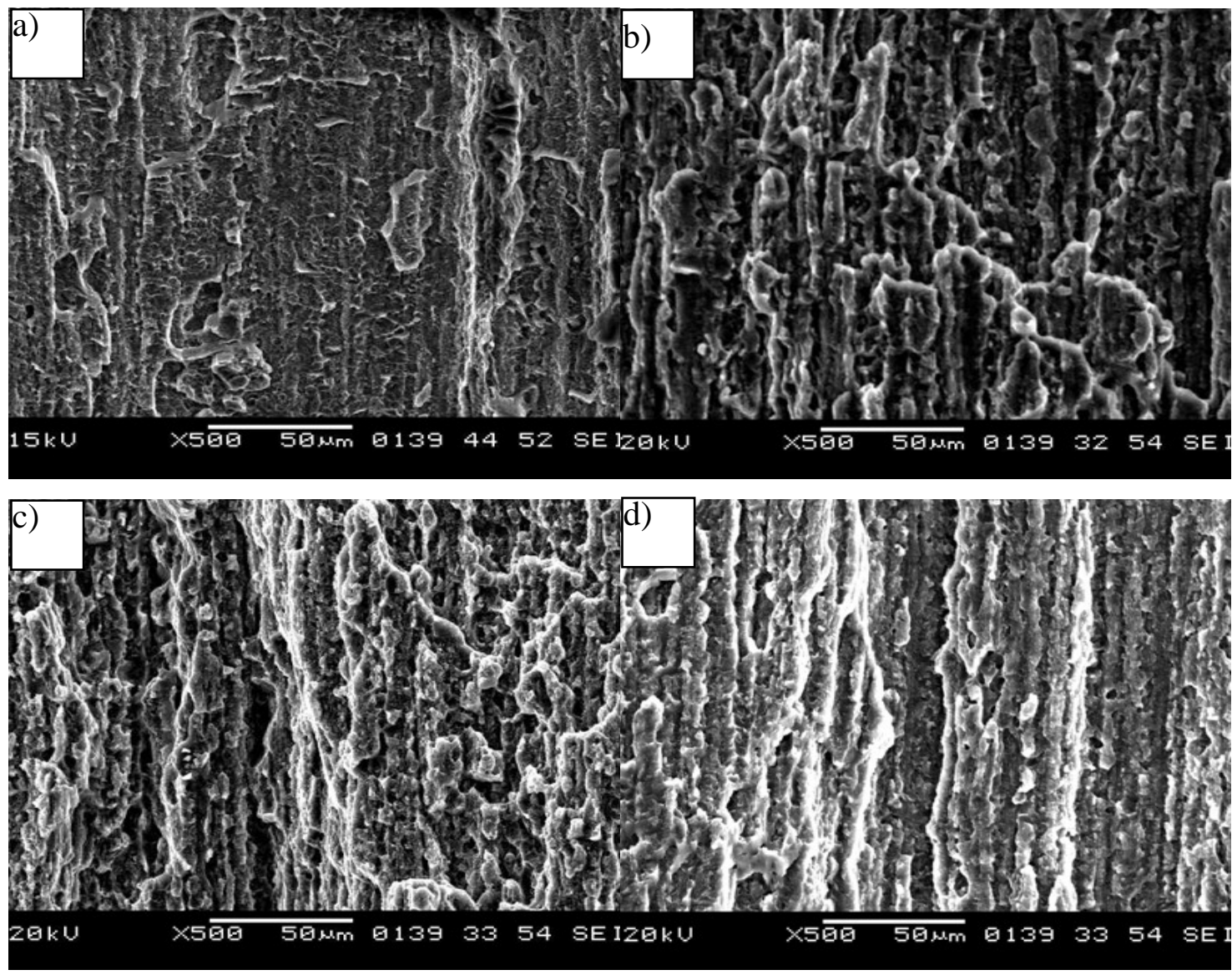

Figure 3 Shear fracture morphology of recycled magnesium alloy with extruding ratio

$$
\text { a) } 4: 1 \text {; b) } 11: 1 \text {; c) } 25: 1 \text {; d) } 44: 1
$$

For the specimens with the extruding ratio of $4: 1$, the fracture surface mainly consists of small facets and no dimple is found and shows a brittle fracture. Fracture trace along the interface 
between chips can be seen, indicating that the bond of chips was weak, which is consistent with the lower shear strength. There are some small dimples on the fracture surfaces for specimens with large extruding ratio shown in Figure 3(b) and (c), and exhibit a ductile fracture.

\section{Conclusion}

AZ31B Magnesium alloy bars were prepared by solid-state recycling with different extruding ratio of 4:1, 11:1, 25:1, 44:1. Shear tests were successfully designed and conducted.

Shear strength of recycled AZ31B magnesium alloy along the extruding direction increases from 94.28MPa to $139.28 \mathrm{MPa}$ when the extruding ratio increases from 4:1 to 44:1, which indicates that the bond between chips was enhanced with the increasing of extruding ratio.

Shear fracture morphology of recycled magnesium specimens show small dimple and ductile deformation mark along shear force. With the low extruding ratio of $4: 1$, fracture surface exhibits flat and brittle fracture increase.

\section{Acknowledgement}

The authors gratefully acknowledge the financial support by National Science Foundation of China(51574100,51404082); Heilongjiang Natural Science Foundation(E2015040); Heilongjiang Educational Office Scientific Research Program(12541793); Jiamusi University research project(Lq2012-31); the Opening Foundation of Material Research and Application Key Lab of the Harbin University of Science and Technology; Jiamusi University collaborative innovation center(2011xtcx2016-03); Jiamusi University Innovation Team(cxtd2013-03) ; Jiamusi University Research project(JMSURCGG2016-006)

\section{References}

[1] Bhuiyan, M.S., Mutoh, Y. Am and Mcevily, J. (2012) The influence of mechanical surface treatments on fatigue behavior of extruded AZ61 magnesium alloy. Mater. Sci. Eng. A, 549(15), 69-75.

[2] Zhang, Q., Li, Q.A., Chen, J and Zhang, X.Y. (2015) Microstructure and ultimate tensile strength of Mg-5Y-3Sm-0.8Ca-(0.1 0.8)Sb alloy. Journal of the Chinese Society of Rare Earths, 6, 718-723.

[3] Imandoust, A., Barrett, C D., Al-Samman, T., Kamala, S. (2017) A review on the effect of rareearth elements on texture evolution during processing of magnesium alloys. Journal of Materials Science,5 2(1):1-29.

[4] Liu, H.H., Ning, Z.L., Yi, J. Y., Ma, Q., Sun, H.C., Huang, Y.J., Sun, J.F. (2017) Effect of Dy addition on microstructure and mechanical properties of Mg-4Y-3Nd-0.4Zr alloy. Trans. Nonferrous Met. Soc. China, 27, 797-803.

[5] Watanabe, H., Moriwaki, K and Muka, T. (2001) Consolidation of machined magnesium alloy chips by hot extrusion utilizing superplastic flow. J. Mater. Sci, 36(20), 5007-5010.

[6] Mabuchi, M., Kubotal, K. (1995) New recycling process by extrusion for machined chips of AZ91 magnesium and mechanical properties of extruded bars. Mater. Trans, 36(10), 1249-1254.

[7] Nakanishi, M., Mabuchi, M and Saito, N. (1998) Tensile properties of the ZK60 magnesium alloy produced by hot extrusion of machined chip. J. Mater. Sci. Lett, 17(23), 2003-2005.

[8] Liu,Y., Li ,Y.Y and Zhang, D.T. (2002) Microstructure and properties of AZ80 magnesium alloy prepared by hot extrusion from recycled machined chips. Trans. Nonferrous Met. Soc. China, 12(5), 882-885.

[9] Wang, J.Y., Lin, Y.N and Lee, S. (2006) Recycling the magnesium alloy AZ91D in solid state. Mater. Trans, 47(4), 1047-1051. 
[10] Chino,Y., Lee, J.S., Nakaura,Y., Ohori, K. and Mabuchi, M. (2005) Mechanical properties of Mg-Al-Ca alloy recycled by solid-state recycling. Mater. Trans, 46(12), 2592-2595.

[11] Zhao, Z.D., Chen, Q., Yang, L., Shu, D.Y. and Zhao, Zh.X. (2011) Microstructure and mechanical properties of Mg-Zn-Y-Zr alloy prepared by solid state recycling. Trans. Nonferrous Met. Soc. China, 21( 2), 265 - 271.

[12]Wu, S.Y., Ji, Z. S., Hu, M., Huang, Z.Q., Tian, C.Y.,Wu, M.Z. (2018) Microstructure and Mechanical Properties of AZ31B Magnesium Alloy Prepared by Solid State Recycling. Rare Metal Materials and Engineering, 47(3), 3169-3175. 
